\title{
ENTRE CRENTES E PAGÃOS: ENSINO RELIGIOSO EM SÃO PAULO
}

\author{
JANAYNA DE ALENCAR LUI \\ Doutoranda do Programa de Pós-Graduação em Sociologia e Antropologia do \\ Instituto de Filosofia e Ciências Sociais da Universidade Federal do Rio de Janeiro \\ janaynalui@gmail.com
}

\section{RESUMO}

O artigo procura refletir sobre as estratégias de atuação dos atores envolvidos no processo de implantação do Ensino Religioso nas escolas públicas do Estado de São Paulo, tendo como foco as relações instituídas no interior do campo estudado. Com a análise da interpretação da Lei de Diretrizes e Bases da Educação Nacional (Lei n.9.394/96) e a posterior modificação de seu artigo n.33 pela Lei n.9.475/97, algumas questões envolvendo a escolha dos conteúdos, capacitação docente e formação do professor aparecem como indicativas para se entender o posicionamento dos grupos envolvidos. Pela participação de grupos como o Conselho de Ensino Religioso de São Paulo, a Associação dos Professores de Ensino Religioso de São Paulo, a Secretaria de Educação do Estado de São Paulo e o Conselho Estadual de Educação é possível compreender a formação do campo de disputa decorrente da implantação da disciplina nas escolas públicas.

EDUCAÇÃO RELIGIOSA - ESCOLAS PÚBLICAS - CURRÍCULOS - SÃO PAULO

\section{ABSTRACT}

BETWEEN BELIEVERS AND NON-BELIEVERS: RELIGIOUS TEACHING IN SÃO PAU$\angle O$. The article seeks to reflect upon the strategies pursued by the actors involved in the process of introducing Religious Education in public schools in the State of São Paulo, focusing the relationships instituted within the field under study. By analyzing the interpretation of the National Education Guidelines (Act n.9.394/96) and the subsequent changes in its article 33 by Act n.947/97, some issues invo/ving the selection of curricular contents as well as teachers' training and formation appear as hints to understand the positioning of the groups involved. The participation on those groups, such as the Religious Education Council of São Paulo, the Association of Religious Teachers of São Paulo, the São Paulo State Education Secretariat and the State Education Council, allows understanding the constitution of this disputed field as consequence of the adoption of this discipline in public schools.

RELIGIOUS EDUCATION - PUBLIC SCHOOL - CURRICULUM - SÃO PAULO

Este trabalho foi extraído de minha dissertação de mestrado (Lui, 2006) apresentada ao Programa de Pós-Graduação em Antropologia Social da Universidade Federal de Santa Catarina - PPGAS/ UFSC. Uma primeira versão deste artigo foi apresentada na 25a Reunião da Associação Brasileira de Antropologia, realizada em Goiânia, de II a I4 de junho de 2006. 
O ensino público no Brasil foi definido como laico pela primeira constituição republicana (| 89|) e regulamentado por leis posteriores. De todas as constituições republicanas a de 189 | foi a única que excluiu totalmente o Ensino Religioso - ER -, ou seja, nas subseqüentes (1934, 1937, 1946, 1967, 1988) ele é inserido como facultativo e permanece até hoje no artigo 210 da Constituição Federal de 1988. Apesar de esse dispositivo aparecer desde 1934, - ER permaneceu fora do rol das disciplinas regulares, pois as Leis de Diretrizes e Bases da Educação Nacional - LDBs - isentavam o Estado do pagamento dos professores (Dickie, 2003).

Por meio de um forte lobby das igrejas cristãs', o ER foi garantido pela Constituição Federal de 1988 (artigo 210 , parágrafo primeiro) e foi constituído como disciplina de oferta obrigatória nas escolas públicas de ensino fundamental, mas de matrícula facultativa aos alunos. Esse lobby se fez mais intenso durante a elaboração da nova Lei de Diretrizes e Bases - LDB -, promulgada em 1996.

Entretanto, a LDB dizia que o ER não poderia ser oferecido com ônus para os cofres públicos. Por isso, o lobby continuou para que o artigo 33 desta lei, em que cabia o tratamento dessas questões, fosse modificado, explicitando a responsabilidade dos estados no pagamento dos professores. Em 1997 foi sancionado o substitutivo do artigo 33, de autoria do Deputado Padre Roque Zimmerman, que define o ER como disciplina normal do currículo das escolas públicas, sendo do Estado a responsabilidade pela contratação dos professores ${ }^{3}$. E ainda manteve o ER como de matrícula facultativa, deixando aos

I. Participaram ativamente desse lobby. a Associação Interconfessional de Educação de Curitiba/ PR - Assintec -, o Conselho de Igrejas para a Educação Religiosa de Santa Catarina - Cier - e o Instituto Regional de Pastoral do Mato Grosso/MS - Irpamat; mas foi o esforço conjunto da Confederação Nacional dos Bispos do Brasil - CNBB -, Associação de Educação Católica do Brasil - AEC - e Associação Brasileira de Escolas Superiores Católicas - Abesc - que conseguiu juntar em uma só emenda a proposta governamental para os estabelecimentos privados visando manter o ensino religioso nas escolas públicas (Cunha, 2005, p. 436).

2. $\bigcirc$ artigo 210 , parágrafo $1^{\circ}$, da Constituição Federal de 1988 assim determina: "O ensino religioso, de matrícula facultativa, constituirá disciplina dos horários normais das escolas públicas de ensino fundamental".

3. A Lei n. 9.475, de 22 de julho de 1997, dá nova redação ao artigo primeiro: Art. $1^{\circ}$ - O art. 33 da Lei n. 9.394, de 20 de dezembro de 1996, passa a vigorar com a seguinte redação: "O ensino religioso, de matrícula facultativa, é parte integrante da formação básica do cidadão e constitui disciplina dos horários normais das escolas públicas de ensino funda- 
Entre crentes e pagãos...

sistemas de ensino a responsabilidade pela definição dos critérios e contratação dos professores, determinando que o ER não pode ser proselitista, nem confessional e que as Secretarias de Educação devem ouvir entidade civil composta por diferentes denominações religiosas sobre a escolha dos conteúdos a serem ministrados pelos professores de ER.

Com isso, o Fórum Permanente de Ensino Religioso - Fonaper ${ }^{4}$ - criado durante a elaboração da LDB, estimulou a formação, nos estados, de Conselhos de Ensino Religioso - Coners - que assumiram ser a "entidade civil" de que fala a lei para funcionar como assessora do Estado na definição de conteúdos. Por sua vez, cabe ao governo estadual efetivamente implantar a disciplina.

No Estado de São Paulo, a discussão sobre a implantação do ER ocorre desde o primeiro mandato do Governador Mário Covas (1994), mas só teve desfecho durante o governo de seu substituto Geraldo Alckmin (Partido da Social Democracia Brasileira - PSDB), com a promulgação da Lei n. 10.783 em 2001 , ou seja, alguns anos após a vigência da nova LDB.

A aprovação da lei no Estado de São Paulo originou-se de um projeto de lei, sob o n. 1.036 em 1999, encabeçado pelo deputado católico José Carlos Stangarlini (PSDB/SP), representante e membro da Renovação Carismática Católica em São Paulo. Também em São Paulo, foi fundado em 1997, um Conselho de Ensino Religioso - Coner/SP - sob a iniciativa de um bispo da Igreja Católica Apostólica Romana e com o apoio da Confederação Nacional dos Bispos do Brasil - CNBB. Este conselho juntamente com a Associação dos Professores de Ensino Religioso - Asper/SP -, também criada em 1997, e na tentativa de se apresentar ao Estado como a "entidade civil" de que

mental, assegurado o respeito à diversidade cultural e religiosa do Brasil, vedadas quaisquer formas de proselitismo.

Parágrafo primeiro - Os sistemas de ensino regulamentarão os procedimentos para a definição dos conteúdos do ensino religioso e estabelecerão as normas para a habilitação e admissão dos professores.

Parágrafo segundo - Os sistemas de ensino ouvirão entidade civil, constituída pelas diferentes denominações religiosas, para a definição dos conteúdos de ensino religioso".

4. O Fonaper é formado por diversas igrejas, cristãs em sua maioria, que coadunam com a idéia de que o ensino religioso deve ser considerado uma "área de conhecimento", com conteúdos que levem o aluno a uma reflexão de cunho "transcendente" (www.fonaper.com.br). 
fala a lei, vêm trabalhando pela efetiva participação nas questões referentes à escolha de conteúdos, admissão de professores e capacitação docente. Esses dois grupos buscam legitimar-se perante a Secretaria de Educação na tentativa de aplicar suas metas e estratégias direcionadas à implantação do ER. As linhas de ação desses dois atores estão voltadas para o reconhecimento dessa legitimidade (Weber, 1999).

\section{O ENSINO RELIGIOSO COMO TRANSMISSOR DE VALORES ÉTICOS}

É importante destacar os termos da legislação estadual para a implantação do ER em São Paulo. Em 9 de março de 200 I foi promulgada a lei paulista, mas em 27 de julho do mesmo ano o Conselho Estadual de Educação CEE - aprovou a Deliberação n. I6, que delimitou os requisitos de formação do professor de ER da seguinte maneira: "de I a a $4^{\mathrm{a}}$ série para portadores de diploma de magistério ou licenciatura em Pedagogia, com habilitação no magistério de $I^{\mathrm{a}}$ a $4^{\mathrm{a}}$ do ensino fundamental, com o ER definido como 'tema transversal' ${ }^{5}$. Para os professores de ER de $5^{\mathrm{a}}$ a $8^{\mathrm{a}}$, exigiu-se graduação em Filosofia, Ciências Sociais ou História, abordando temas relacionados à "história das religiões" e que levassem o aluno à apreensão de valores relacionados à cidadania. Mas em que se baseiam esses valores?

Outras questões aparecem na interpretação da lei dada pelo legislador paulista como características da contraditória relação entre a Secretaria da Educação e os grupos religiosos. A primeira é a formação do professor, que excluiu profissionais de Ciências da Religião em prol de maior neutralidade em sala de aula; a segunda é a caracterização do ER como "tema transversal" nas quatro primeiras séries. Muito embora São Paulo seja um dos pólos de formação em Ciências da Religião, esses profissionais não foram considerados aptos a ministrar o ER segundo as normas pedagógicas do Conselho Estadual de Educação, mesmo porque os cursos oferecidos não são de licenciatura. Em nota divulgada pela imprensa católica ${ }^{6}$, o Deputado Stangarlini - autor do projeto

5. Para o MEC, "temas transversais" são aqueles "voltados para a compreensão e construção da realidade social e dos direitos e responsabilidades relacionados com a vida pessoal e coletiva, e com a afirmação do princípio da participação política" (www.mec.gov.br).

6. "Ensino religioso também para São Paulo", 2001. 
Entre crentes e pagãos...

de lei - considera controversos esses aspectos da lei paulista e sustenta que a inclusão de profissionais formados em Ciências da Religião ainda "é uma meta a ser buscada".

A inclusão do ER como "tema" provocou reações tanto de grupos religiosos que consideram esta opção uma forma de descaracterizar o ER como área de conhecimento 7 ; quanto de grupos laicos, que consideram esse aspecto da lei uma imposição da disciplina ao aluno, uma vez que integra o conteúdo das disciplinas já existentes. Para Luiz Antônio Cunha" " "a oferta do ER pelo professor da classe (nas quatro primeiras séries do ensino fundamental) vai de encontro ao caráter facultativo da lei, tanto para alunos quanto para professores. Ou seja, obriga alunos e professores a assistirem e ministrarem o ER".

A lei paulista também determina que seja ouvida uma "entidade civil" em relação à escolha dos conteúdos. Há que se considerar que o projeto de lei de 1999 fazia referência somente à participação do Coner/SP quanto à escoIha dos conteúdos. Esse termo foi modificado pela lei de 200 I , fazendo constar que "outras entidades civis representativas das diferentes denominações religiosas" também deveriam ser ouvidas. Esse tópico foi reafirmado pelo Governador pelo Decreto n. 46.802/2002. A supressão da participação exclusiva do Coner/SP deu início à disputa entre os grupos religiosos e o Estado.

De fato, a Secretaria ouviu o Conselho Estadual de Educação no que se refere à escolha de conteúdos, muito embora não seja deste órgão tal atribuição. Além disso, a definição dos conteúdos da deliberação aprovada pelo CEE está voltada para a reflexão sobre a cidadania no universo escolar. $O$ ER, portanto, se justificaria por uma perspectiva antropocêntrica, voltada para a relação entre os homens e não dos homens com Deus, funcionando como provedor e transmissor de valores morais e atuando como elemento formador, argumento esse que associa "religião" à "moral" (Dickie, 2003; Giumbelli, 2004).

7. A Resolução n. 2, de 7 de abril de 1998, da Câmara de Educação Básica do Conselho Nacional de Educação, diz que a "educação religiosa é uma das áreas de conhecimento, em conformidade com as demais áreas" (Brasil, 1998).

8. Fala extraída da participação do professor Luiz Antônio Cunha no Seminário Religião na escola: Pontos e Contrapontos, promovido pelo Núcleo de Estudos da Religião (Departamento de Pós-Graduação em Ciências Sociais - DPCIS/ Universidade Estadual do Rio de Janeiro Uerj), pelo Programa de Pós-Graduação em Sociologia e Antropologia/UFRJ e pelo Pronex "Movimentos religiosos no mundo contemporâneo", Rio de Janeiro, 6 de dezembro de 2005. 
A lei abre, ainda, a possibilidade da oferta do ensino religioso confessional fora do horário curricular, ministrado por autoridades religiosas que podem utilizar o espaço da escola para realizar suas atividades voluntariamente.

A capacitação docente ocorreu mediante a contratação de dois professores do Departamento de História da Universidade Estadual de Campinas Unicamp -, que elaboraram cinco apostilas sobre "história das religiões", discutindo questões como tolerância, diversidade religiosa e analisando a religião do ponto de vista histórico e cultural.

Esse material foi apresentado aos Assistentes Técnico Pedagógicos - ATPs das Diretorias de Ensino do Estado de São Paulo, em dois encontros ocorridos na capital. A Secretaria disponibilizou um site (www.ensinoreligioso.com.br), ministrado por doutorandas em História da Unicamp, que foram habilitadas pelos capacitadores para responder às dúvidas dos professores de ER sobre o conteúdo das apostilas. Os autores das apostilas acreditam que "ensinar religião (e não uma religião) na escola não deve ser feito para defesa de uma delas, em detrimento de outras, mas discutindo-se princípios, valores, diferenças e tendo em vista a compreensão do outro". Para eles o ensino de religiões como exercício de alteridade, este sim pode ser o conteúdo trabalhado na escola pública (Karnal, Silva, 2002, p.8).

Ao apresentar o mesmo material, o Secretário de Educação, por sua vez, define a disciplina, com certa ênfase religiosa:

O ensino religioso tem que ser uma ponte que conduza os estudantes ao caminho do bem, aos valores humanistas construídos com as bases sólidas do amor, da fraternidade, da bondade, da honestidade, da humildade e principalmente do respeito àqueles cujas opiniões divergem das nossas. São conceitos, infelizmente, cada vez mais escassos num mundo onde prevalece a coisificação provocada pelo materialismo. É papel dos estudantes lutar para reverter esse quadro, sob pena de comprometermos a qualidade do futuro de nossas gerações. (Chalita, 2002, p.5-6).

A capacitação e o material elaborado pela Unicamp não foram bem recebidos pelos grupos religiosos, principalmente pela Asper/SP, que criticou a escolha do Conselho Estadual de Educação pelo conteúdo "história das reli- 
Entre crentes e pagãos...

giões". A Asper tem como pressuposto que o ER não pode se limitar à História e que, com isso, o ER perdeu sua característica de disciplina autônoma e de área de conhecimento. Este também é o argumento principal do Fonaper, ou seja, de que o ER deve ter o mesmo reconhecimento que as demais disciplinas de formação básica e que sua oferta é "um direito do aluno".

Ressalte-se, ainda, que para o Fonaper a finalidade do ER é "subsidiar o conhecimento através do tratamento didático" de eixos de conteúdos que incluem: culturas e tradições religiosas; escrituras sagradas e/ou tradições orais; teologias; ritos e ethos, para ir "sensibilizando para o mistério, capacitando para a leitura da linguagem mítico simbólica e diagnosticando a passagem do psicosocial para a metafísica/transcendente" (Parâmetros, www.fonaper.com.br). Esses são os mesmos fundamentos do Coner/SP e da Asper/SP, para o ER nas escolas públicas.

É compreensível que os grupos favoráveis à implantação do ER na escola pública, na maioria cristãos, tenham se ressentido quanto à opção do estado por ensinar "história das religiões". Considerando que a Igreja Católica mantinha o monopólio das aulas de ER no estado, antes da LDB de 1996, não há como esperar reação diversa 9 . De certa forma, o Estado, pela implantação dessa configuração do $\mathrm{ER}$, retirou a legitimidade das autoridades religiosas para ministrar o ER, devendo estas se submeter ao crivo da Secretaria de Educação e principalmente ao interesse da escola. E ainda, o ER, utilizado pelo estado como mecanismo de controle, tenta retirar o "religioso" da matéria, utilizando-se da "História", com a justificativa do não-proselitismo.

Algumas questões são importantes para entendermos o sentido da interpretação da lei em São Paulo: primeiro, a utilização pela Secretaria do termo "História" como garantia do não-proselitismo, e segundo, a posição contraditória dos representantes do estado (Governador e Secretário da Educação).

Ainda que a intenção em São Paulo seja preservar a laicidade do estado, dando ao ER uma visão antropocêntrica no sentido de funcionar como

9. O Decreto n. 12.323, de 25 de setembro de 1978, garantia que o ensino religioso nas escolas públicas de São Paulo seria ministrado pelas autoridades eclesiásticas credenciadas, preservando a confissão religiosa do aluno. Tais autoridades eram responsáveis pelo programa das atividades curriculares, envolvendo planejamento, execução e fiscalização do ensino religioso (São Paulo, 1978). 
provedor de valores que interfiram nas relações humanas, é interessante observar o que descreve o artigo $2^{\circ}$ do Decreto n. 46.802, baixado pelo Governador Geraldo Alckmin, em 5 de junho de 2002:

O ensino religioso a ser ministrado no horário normal das escolas estaduais terá caráter supraconfessional, devendo assegurar o respeito a Deus, à diversidade cultural e religiosa e fundamentar-se em princípios de cidadania, ética tolerância e em valores universais presentes em todas as religiões. (grifos meus)

O governador deixa transparecer a idéia de um Deus único e universal, explicitando sua visão teísta, o que mina o tom relativista pretendido. Uma posição baseada em valores cristãos também aparece no relatório da Deliberação n. 16/200l, do Conselho Estadual de Educação:

... as propostas de ensino religioso devem enfatizar o respeito pelo outro, o trabalho com aqueles que se encontram em situação de exclusão social, promovendo formas voluntárias e autônomas de participação e levando a um compromisso com as questões sociais e a uma possibilidade de intervenção: tais práticas são caminhos viáveis para a promoção da cidadania. Do mesmo modo, o compromisso com valores como honestidade, justiça, amor ao próximo, bondade e solidadriedade devem ser incentivados. Estes valores ligados a uma ética que, especifica para cada grupo social e religioso, apresenta elementos que podem ser vistos como universais, devem ser assumidos na organização dos temas. ("O conteúdo", cap II, www.ceesp.sp.gov.br/Deliberacoes/de_I6_0I.htm., grifos meus)

Isso dá a entender, portanto, que o exercício pleno da cidadania está associado a valores ético-religiosos, uma vez que o relatório da deliberação do CEE apresenta conceitos como fraternidade, amor ao próximo, bondade e solidariedade como ideais para caracterizar um "bom" cidadão. Como se somente os mais "religiosos" fossem efetivamente capazes de exercer a cidadania! Dessa maneira, observamos que a aplicação e a interpretação da LDB em São Paulo foi cercada por muitas contradições. 
Entre crentes e pagãos...

\section{CONER/SP E ASPER/SP: GRUPOS RELIGIOSOS EM QUESTÃO}

Pela análise da atuação do Coner e da Apser podemos compreender a relação estabelecida entre as autoridades religiosas e a Secretaria, bem como, os diferentes posicionamentos sobre a implantação do ensino religioso em São Paulo e os limites impostos pelo estado aos grupos religiosos.

O Coner formou-se inicialmente por denominações cristãs, sob a liderança da Igreja Católica Apostólica Romana e com o incentivo da CNBB/Regional Sul I. Com a presidência do grupo ocupada por um bispo católico da linha progressista, de 1997 até 2003, o Conselho se mantinha apenas cristão, até encontrar resistência no diálogo com a Secretaria.

As igrejas que participaram da criação do Coner/SP são as mesmas que formam um grupo chamado Movimento de Fraternidade de Igrejas Cristãs Mofic $^{10}$. A sede do Coner/SP continuou sendo a mesma do Mofic, ou seja, a Casa da Reconciliação de São Paulo", entidade que reúne diversos grupos religiosos ligados à promoção do que chamam "diálogo inter-religioso". Ainda que tenha reunido somente igrejas cristãs, desde a sua formação o Coner pretendia configurar-se como a "entidade civil" assessora do estado.

O Coner/SP'2, em documento próprio, se define como uma instituição de direito privado, de natureza associativa, apolítica, sem fins lucrativos, com número ilimitado de sócios. Este conselho esperava atuar junto à Secretaria na implantação do ER, como mostra a passagem de um histórico de suas atividades:

10. Formam o Mofic: Igreja Católica Apostólica Romana, Igreja Metodista, Igreja Evangélica de Confissão Luterana, Igreja Armênia Apostólica, Igreja Presbiteriana Unida, Igreja Episcopal Anglicana do Brasil, Igreja Cristã reformada do Brasil.

I I. Para um maior esclarecimento sobre os grupos que pertencem à Casa da Reconciliação ver: www.casadareconciliacao.com.br.

12. Os principais objetivos do Coner/SP são "abarcar as denominações religiosas interessadas, com o objetivo específico de constituírem-se em entidade civil, para os fins previstos em lei; somar forças na busca de meios e condições que assegurem a tutela do direito de liberdade de consciência e confissão religiosa e do direito ao ensino religioso como parte integrante, ao menos da formação básica do cidadão; colaborar com as competentes autoridades na regulamentação dos processos para a definição da formação e execução dos conteúdos básicos urgindo o cumprimento das mesmas e apoiar a formação de profissionais para o ensino religioso" (Documento do Coner/SP, www.casadareconcicilacao.com.br). 
Acreditamos que o ensino religioso não tendo um caráter doutrinário deve valorizar a pessoa na sua totalidade, aceitando e respeitando as suas diferenças e características, pois a busca de sentido para a própria vida é um direito de todo ser humano independente da religião e da fé que professa. Numa sociedade em que a superficialidade das relações se tornam tão fortes, é muito importante o desenvolvimento integral do indivíduo. Esperamos que o ensino religioso, uma das áreas do conhecimento, se apresente da forma mais agradável possível, para que a religiosidade latente em cada um seja despertada e que possibilite uma estabilidade pessoal. Temos enfrentado muitas dificuldades para a implementação do ensino religioso nas nossas escolas, pois falta conhecimento por parte dos pais e vontade política para que esta disciplina seja realmente implantada de acordo com a lei. Portanto esperamos que cada grupo religioso participe deste momento muito importante, divulgando o texto da lei entre os seus membros, enviando-o às escolas próximas e aos grupos religiosos próximos que não fazem parte do Coner/SP, conscientizando os pais que este é um direito de todo aluno. Não podemos ter medo do novo, mas sim assumi-lo como um desafio e uma responsabilidade ${ }^{13}$. (www.casadareconciliacao.com.br)

Coner por meio de seu estatuto restringiu a entrada de muitas religiões ao determinar que somente as instituições religiosas registradas em cartório há mais de cinco poderiam se filiar. Com a formação cristã, o Coner não atingiu reconhecimento perante o estado sob a alegação de ser confessional.

Buscando atingir o status de assessor do estado na escolha dos conteúdos, o Coner decidiu abrir suas portas para denominações religiosas que trouxessem mais visibilidade ao grupo. Portanto, há aproximadamente dois anos, aliou-se ao Conselho Parlamentar pela Cultura de Paz - Conpaz ${ }^{14}$-, um grupo que está ligado à Assembléia Legislativa do Estado de São Paulo e que reúne diversas religiões.

13. Esse documento em que o Coner/SP expõe sua definição do ER está sem data. Pelas entrevistas com os membros mais antigos, acredita-se que quando este se refere à "lei", é da LDB que estão falando e não da lei estadual.

14. Criado em 2002, tem sede na Assembléia Legislativa do Estado de São Paulo. É composto por membros de diversas entidades religiosas, representantes de organizações e de movimentos sociais e por deputados. Somente alguns religiosos participam do Coner/SP. 
Entre crentes e pagãos...

Com essa abertura, o Coner agregou integrantes ${ }^{15}$ que participam de discussões sobre o ER na escola pública, mas que são contrários à presença da religião na escola. Muitos deles - não cristãos - acreditam que se as idéias cristãs continuarem prevalecendo, o ER terá características de catequese. A busca por um Coner mais plural resultou em diferentes posições dentro do grupo, por isso a atuação é pouco articulada e o plano de ação praticamente ineficaz. Em decorrência da falta de consenso, o grupo promoveu um "seminário de capacitação interna ${ }^{16 ", ~ p a r a ~ o ~ e s c l a r e c i m e n t o ~ d e ~ q u e s t o ̃ e s ~ r e f e r e n t e s ~}$ à legislação sobre o ER e também para convencer os novos integrantes da importância da implantação do ER na escola pública.

Antes dessa "abertura", o Coner mantinha um vínculo com a Asper que atualmente procura individualizar suas estratégias e acompanhar as decisões da Secretaria e do Conselho Estadual de Educação. A Diretora da Asper acredita que a capacitação promovida pelo Estado foi como "jogar pérolas aos porcos, pois as escolas não conseguiram aplicar o que foi repassado". A Asper é formada por religiões cristãs e está hoje com poucos membros, já que a deliberação do CEE fez que perdessem o apoio da Coordenadoria de Ensino da Grande São Paulo (COGSP).

Essa associação reivindica junto à Secretaria o esclarecimento de três tópicos: a. o reconhecimento do ensino religioso como "área de conhecimento"; b. a formação específica do professor nas quatro primeiras séries do ensino fundamental e, c. a efetiva implantação do ER nas escolas, já que poucas são as que oferecem a disciplina.

Percebendo que o órgão competente para responder às suas requisições era o Conselho de Educação, a Diretora da Asper encaminhou ofício pedindo esclarecimentos sobre a deliberação CEE n. 16, que trata da formação de professores e escolha de conteúdos. Para ela a opção por "história das religiões foi uma forma da Secretaria não se comprometer".

15. Esses "novos integrantes", apesar de não filiados por causa da restrição estatutária, participam das atividades do Coner e acompanham a tomada de decisões, mas sem direito a voto.

16. Seminário realizado pelo Coner/SP, em junho de 2005, sob o título Em Busca de uma Proposta de Educação Inter-Religiosa pela Cultura de Paz: Ouvir para Compreender. Foram convidados a participar do Seminário: representantes do CEE, professores de ER, pais e alunos. Nenhum representante do estado compareceu ao evento. 
Além da Asper e do Coner, representantes de diversas religiões se posicionaram sobre a implantação do ensino religioso em São Paulo. Destaco partes de algumas entrevistas:

A escola pública é um ambiente inapropriado para a instrução religiosa. Para que o ensino religioso pudesse cumprir seus objetivos, seria necessário que os professores fossem dotados de altíssimo grau de sensibilidade, discernimento e equilíbrio, a fim de não imporem, nem mesmo sub-liminariamente, sua própria linha religiosa aos alunos. (Rabino Henry Sobel, presidente da Comunidade Israelita Paulista e Coordenador da Comissão Nacional de Diálogo Religioso CatólicoJudaico, órgão da CNBB; entrevista por correio eletrônico, jun. 2005)

O próprio mecanismo do momento cai para você fazer o catecismo. Esse é o rebanho que eu tenho, pensa o professor. Enfim, isso não serve para nada. De qualquer lugar que você olhe, o ensino religioso vai acabar. A base em que ele (ER) foi implantado está podre. (Representante da Comunidade Zen-Budista em São Paulo, coordenada pela Monja Cohen, entrevista, maio 2005)

.... os padres, o próprio atual bispo, tem a inocência de imaginar que uma professora de confissão evangélica vai ter boa vontade em ensinar uma religião que não a sua. Acho que o Estado deveria parar, isso é uma maluquice, isso é uma nova catequese, esse é um novo proselitismo religioso, é uma imposição que o governo está fazendo. (Pai Francelino de Shapanan, representante da Tradição Afro-Brasileira, Tambor de Mina Jêje Nagô, entrevista, jul. 2005)

○ importante é passar o valor transcendente, sair da visão de grupo. $\bigcirc$ ensino religioso é importante para dar a noção de Deus, a noção da responsabilidade social, da solidariedade para que a nossa juventude já tenha um pouco de ética no seu comportamento. (Monsenhor Arnaldo Beltrani, porta-voz do arcebispo de São Paulo D. Cláudio Hummes, apud Valdejão, 200 I, p.66)

Verifica-se, assim, que as três primeiras colocações são contrárias à presença do ER na escola pública, baseadas na premissa de que a escola não deve ceder lugar à religião. $O$ último posicionamento combina, de certa forma, com algumas diretrizes do estado - principalmente no que tange à transmissão de valores éticos - e não podia ser outro senão de um representante católico. 
Entre crentes e pagãos...

Dessa forma, a pesquisa mostrou, em um primeiro momento, que o espaço da escola pública aparece em disputa e esta abrange interesses próprios do Estado laico em contraposição aos interesses das instituições religiosas, na medida em que surgem novas configurações e que estratégias são colocadas em prática. Alio-me ao entendimento de Giumbelli ${ }^{17}$ de que a implantação do ER em São Paulo é mais uma forma de definição e regulação do espaço público pelo Estado e nos permite pensar o lugar que tem a religião na modernidade.

\section{CONSIDERAÇÕES FINAIS}

Não há dúvida de que o ensino religioso nas escolas públicas permanece polêmico. Seja pela forma como é implantado nos diferentes estados ${ }^{18} \mathrm{da}$ federação, seja pela maneira com que é oferecido nas escolas. Em São Paulo, a disputa envolveu a escolha dos conteúdos, a capacitação docente e, principalmente, o limite imposto pelo Estado à participação dos grupos religiosos. A Igreja Católica marcou presença aliando-se a outras igrejas cristãs para a manutenção do "religioso" na escola, através da atuação do Coner/SP.

Apesar do apoio e incentivo da Igreja Católica e de seu privilégio junto ao estado como representante da Religião, o Coner/SP não conseguiu ainda esse reconhecimento. Isto se deve, em parte, ao jogo político interno dos diferentes órgãos estatais que controlaram a implantação do ER em São Paulo, jogo no qual prevaleceu a visão de religião como parte da história e do contexto social e não como verdade. Ainda assim, numa aparente contradição, o valor da Religião para a construção da cidadania inclui uma consideração etnocêntrica dos valores morais que o ER poderia transmitir e consolidar nos alunos. Etnocêntrica porque está calcada em valores cristãos que projetou para a totalidade das religiões.

17. Giumbelli (2002, p.5I) esclarece que o uso que faz do termo "regulação" se associa "à constatação de que vivemos em sociedades que concebem o mundo como algo repartido em esferas, entre as quais figura a religiosa, e que precisam elaborar formas de administrar essas repartições. Essas formas, compostas por representações, instituições e práticas são definidas historicamente e podem sofrer mutações, mais ou menos aceleradas".

18. Pelo trabalho de Giumbelli e Carneiro (2004), podemos ter um panorama da implantação do ensino religioso no Rio de Janeiro. Outro modelo de implantação é analisado por Dickie (2003), em Santa Catarina. 
A recusa do estado em ouvir o Coner foi, por sua vez, reforçada pelo fato de este, à época da implantação do ER, ser totalmente cristão, o que foi compreendido pelos órgãos do estado como "religioso demais". Na sua função de regular o espaço da Religião, o estado também recusou a perspectiva da Asper/SP, que abraçou os preceitos do Fonaper, para o qual a religião deveria aparecer no espaço da escola pública pelo seu valor de verdade.

No entanto, pela análise da busca de legitimação do Coner/SP e da Asper/SP, notamos que a inclusão do ER em São Paulo somente se deu em virtude de uma luta intensa das igrejas cristãs, que se mantêm até hoje em posição de destaque. Nesse processo, a Igreja Católica atuou nos bastidores para reafirmar sua posição, por meio das investidas da CNBB.

Ao acompanhar a tentativa de consolidação do Coner/SP como "entidade civil assessora do Estado", percebemos que as estratégias baseadas nas diretrizes cristãs foram ineficazes, porque marcaram a confessionalidade do grupo, afastando-o da negociação com o estado. Esta marca provocou uma mudança de estratégia do Coner/SP, que se abriu à participação de outras denominações religiosas - facilitando e relativizando as normas de participação. Essa abertura, apesar de efetivada, não é consensual no Coner/SP e não trouxe, até agora, o resultado esperado de consolidação da imagem de um Coner multirreligioso. Se antes eram as igrejas cristãs, que dispunham, nos diferentes estados, da educação religiosa, hoje são elas que temem perder esse espaço para "outras" religiões, optando por aliar-se a elas e assim controlar o espaço que pretendem continuar ocupando.

No entanto, na medida em que a pesquisa avançou, questões envolvendo um jogo de poder tornaram-se cada vez mais claras nas relações internas ao grupo. Se o que fez o Coner aliar-se a outras religiões foi o fracasso de suas investidas perante a Secretaria, os não-cristãos, por sua vez, aceitaram o convite cientes de que sua participação era limitada e que a supremacia continuaria a ser cristã, mas acreditando na tentativa de legitimar-se como Religião no espaço público.

Tudo isso traz à tona um movimento que não é novo: as relações entre política e religião. Na verdade esse vínculo nunca se rompeu por estar historicamente construído, e apontar para uma configuração do religioso que introduz um deslocamento de fronteiras ou uma ressignificação de práticas (Burity, 200 I). Para o autor, tem havido uma "publicização do religioso" e, de certa 
Entre crentes e pagãos...

forma, uma reabertura do espaço público à religião. Isso não deixa de ser verdade se pensarmos numa escola pública preocupada em oferecer valores ético-religiosos, relacionando-os ao exercício pleno da cidadania, como acontece em São Paulo. Neste caso não seria somente uma "abertura ao religioso", mas a ocupação de um espaço disponibilizado pela lei, pelo Estado, portanto, e regulado por esse mesmo Estado. Em São Paulo, a religião aparece como "rival" da escola laica (Dickie, Lui, 2005).

Esse campo, assim configurado, está em constante mutação, na medida em que novos atores aderem ao debate, já que o governo do município da capital também pretende incluir o ER nas escolas ${ }^{19}$. A questão do ER nas escolas abriu espaço para questões já existentes, mas que estavam adormecidas na esfera pública, tais como o alcance da legitimidade do Estado laico na decisão sobre assuntos em que o "religioso" aparece. A religião, por sua vez, se viu intimidada.

Apesar da relação de proximidade do Secretário da Educação, Gabriel Chalita, e do Governador do Estado, Geraldo Alckmin, com a Igreja Católica, a escolha da história das religiões como conteúdo do ER, feita pelo Conselho Estadual de Educação, aconteceu independentemente de qualquer influência dessas autoridades. Isso não significou que, ao dispensarem a responsabilidade pela escolha dos conteúdos, não se mantiveram fiéis aos movimentos religiosos aos quais se vinculam.

Essas questões teriam influenciado a argumentação contida na deliberação do Conselho Estadual de Educação quanto à definição do que seria o ER na escola pública. Evidenciam a preferência por valores relacionados à moral e a atrelam à religião. Trata-se de valores que aparecem para o Governador, como basilares ao exercício da cidadania, o que torna a "rivalidade" entre o Estado e a Religião, em São Paulo, paradoxal. Portanto, o conceito de cidadania acionado pelo Estado, em São Paulo, não só justifica e limita o espaço do religioso na escola pública, como evidencia que ele está calcado sobre os valores cristãos da

19. A Folha de S. Paulo, de 4 de julho de 2006, publicou matéria referente à aprovação, pelo prefeito de São Paulo, Gilberto Kassab (Partido da Frente Liberal - PFL), da lei que inclui o ensino religioso no currículo escolar do ensino fundamental das escolas públicas municipais. O texto do diploma legal é de autoria do vereador Domingos Dissei (PFL) que mantém os termos da lei estadual quanto ao não-proselitismo e à matrícula facultativa. A efetiva implantação ainda não foi realizada. 
tolerância, amor ao próximo, fraternidade. Não obstante, o Estado não se reconhece como devedor do credo cristão e faz da regulamentação do ER e de sua implantação um mecanismo de regulação da Religião na esfera pública.

Resta saber se o que efetivamente é repassado aos alunos nas escolas públicas de São Paulo condiz com a "neutralidade" sugerida pelo Conselho Estadual de Educação e, também, como esses alunos - principais interessados - recebem a "nova" disciplina. Dito de outra forma, quais os limites estabelecidos pelo Estado por meio da regulação do espaço ocupado pela Religião na escola pública?

\section{REFERÊNCIAS BIBLIOGRÁFICAS}

BRASIL. Conselho Nacional de Educação. Câmara de Educação Básica. Resolução CEB n. 2, de 7 de abril de 1998. Brasília, 1998.

BRASIL. Ministério da Educação e Cultura. Disponível em: http//:www.mec.gov.br. Acesso em: out. 2005.

BURITY, J. Religião e política na fronteira: desinstitucionalização e deslocamento numa relação historicamente polêmica. Revista Rever, São Paulo, v. I , n.4, p.27-45, 200 I .

CHALITA, G. Um novo horizonte. In: KARNAL, L.; SILVA, E. O Ensino religioso nas escolas públicas do Estado de São Paulo. São Paulo: Cenp, 2002. p.5-6.

CUNHA, L. A. Educação, estado e democracia no Brasil. São Paulo: Cortez. 2005. A Educação no processo constituinte.

DICKIE, M. A. S. Todos os caminhos levam a Deus: o CONER e o ensino religioso em Santa Catarina, 2003. Trabalho apresentado no $27^{\circ}$ Encontro Nacional da Anpocs. Caxambu, out. 2003. (GT Religião e Sociedade)

DICKIE, M. A. S.; LUI, J. de A. O Ensino religioso e a interpretação da lei. Trabalho apresentado em $13^{\circ}$ Jornadas sobre Alternativas Religiosas na América Latina, 13. Porto Alegre, set. 2005. (GT Religião, Poder e Política)

ENSINO religioso também para São Paulo. Mundo e Missão, v. I I, n.39, 200 I. Disponível em: http://www.pime.org.br/mundoemissao/educacaoensino.htm. Acesso em: out. 2005.

ESCOLAS da prefeitura terão ensino religioso. Folha de S. Paulo. Disponível em: http//: www.folhaonline.com.br. Acesso em: 4 jul. 2006.

FÓRUM PERMANENTE PARA O ENSINO RELIGIOSO - Fonaper. Parâmetros curriculares. Disponível em: http//:www.fonaper.com.br. Acesso em: ago. 2005. 
Entre crentes e pagãos...

GIUMBELLI, E. O Fim da religião: dilemas da liberdade religiosa no Brasil e na França. São Paulo: Attar, 2002.

Religião, estado e modernidade: notas a propósito de fatos provisórios. Estudos Avançados, São Paulo, v. 18, n.52, p.47-62, 2004.

GIUMBELLI, E.; CARNEIRO, S. M. de S. Ensino religioso no Estado do Rio de Janeiro: registros e controvérsias. Comunicações do ISER, Rio de Janeiro, v. 23, n.60, 2004.

KARNAL, L.; SILVA, E. O Ensino religioso na escola pública de São Paulo. São Paulo: Secretaria do Estado da Educação, 2002. (Apostila, I -4)

LUI, J. de A. Em nome de Deus. um estudo sobre a implementação do ensino religioso nas escolas públicas de São Paulo. Florianópolis, 2006. Dissert. (mestr.) Programa de Pós-Graduação em Antropologia Social, Centro de Filosofia e Ciências Humanas, Universidade Federal de Santa Catarina.

Entre crentes e pagãos: o ensino religioso nas escolas públicas de São Paulo. Trabalho apresentado na 25a Reunião Brasileira de Antropologia. Goiânia, I I - 4 jun. 2006. (GT 44)

SÃO PAULO. (Estado). Conselho de Ensino Religioso do Estado de São Paulo. Documento do CONER/SP /999. Disponível em: http//:www.casadareconciliacao.com.br. Acesso em: set. 2004.

SÃO PAULO (Estado). Conselho Estadual de Educação. Deliberação CEE n. 16/200/: regulamenta o artigo 33 da Lei n.9.394/96. São Paulo. 200 I.

SÃO PAULO (Estado). Governo do Estado de São Paulo. Decreto n. 46.802, de 5 de junho de 2002: dispõe sobre o ensino religioso nas escolas públicas estaduais de ensino fundamental e dá outras providências correlatas. São Paulo. 2002.

SÃO PAULO (Estado). Secretaria Estadual de Educação. Decreto n. 12.323, de 25 de setembro de 1978: regulamenta o ensino religioso nas escolas de $1^{\circ}$ e $2^{\circ}$ graus. São Paulo, 1978.

VALDEJÃO, R. Religião será facultativa para os alunos. Folha de S. Paulo, C.5, p.66, 18 ago. 2001 .

WEBER, M. Economia e sociedade: fundamentos da sociologia contemporânea, I. Brasília: Editora da UnB, 1999. Os Tipos de dominação.

Recebido em: dezembro 2006

Aprovado para publicação em: janeiro 2007 